\title{
Novel Bio-Markers for Prediction of Pre-eclampsia
}

\section{Garg R $\mathbf{R}^{1}$, Singh $\mathrm{S}^{2}$, Dhiman $\mathrm{S}^{3}$, Agrawal $\mathbf{P}^{4}$, Prakash $\mathbf{P}^{5}$}

${ }^{1}$ Assistant professor, ${ }^{2}$ Professor and Head, ${ }^{3}$ Senior Resident, ${ }^{4}$ Department of Anesthesiology, Apollo Gleneagles Hospital, Kolkata, India, ${ }^{5}$ Associate Professor of Medicine, Department of Obstetrics and Gynaecology, SN Medical College, Agra, India.

Received: April 7,2016; Accepted: May 1,2016

Pre-eclampsia is a pregnancy related disorder. It is an important cause of maternal and perinatal morbidity and mortality worldwide. Two to eight percent of pregnancies were affected by pre-eclampsia. It is characterized by de novo hypertension and proteinuria after 20 weeks of gestation. The etiology and pathogenesis of the disease is unknown, but recent studies have revealed that placenta is the place of origin of this disorder and widespread maternal endothelial dysfunction is the characteristic feature of the disease. Some biochemical molecules are identified recently which are involved in the pathogenesis of the disease, which may help in early identification of patients at risk and help in providing proper prenatal care. Several promising biomarkers have been proposed, alone or in combination. Maternal serum concentrations of these biomarkers either increase or decrease in pre-eclampsia during gestation. This review focuses on the various biomarkers available and their utility in prediction and diagnosis of pre-eclampsia.

Keywords: biomarkers, hypertension, preeclampsia, proteinuria

\section{INTRODUCTION}

Pre-eclampsia (PE) is one of the most common complication in pregnancy. It is an important cause of maternal and perinatal morbidity and mortality. Two to eight percent of pregnancies were affected by PE. ${ }^{1}$ It is characterized by de novo hypertension and proteinuria after 20 weeks of gestation. Renal failure, pulmonary edema, coagulopathy, neurological damage is common complications occurring in preeclamptic patients. More than 50,000 maternal deaths annually occur due to PE worldwide. ${ }^{2,3}$

$\mathrm{PE}$ can be classified into early-onset PE occurring before 34 weeks of gestational age and late-onset PE which develops after 34 weeks of gestational age. Early-onset PE is commonly associated with fetal growth restriction (FGR), abnormal uterine and umbilical artery Doppler waveforms and adverse maternal and perinatal outcomes, whereas a mild form of maternal and fetal involvement with usually a favorable perinatal outcome is seen in late onset PE. 4-6 About one third of maternal mortality is caused by PE in developing countries due to poor health care facilities. ${ }^{7}$ In India, incidence of PE and eclampsia

\section{CORRESPONDENCE}

Dr Ruchika Garg

Assistant Editor JSAFOG

Assistant Editor JSAFOMS

ruchikagargagra@gmail.com

Agra, India. is around $4.6 \%$ and the neonatal mortality rate is around 43 per 1000 live births. ${ }^{8,9}$

$\mathrm{PE}$ is considered a multisystem disorder and unfortunately its pathophysiology is still unclear. As we see there is a great impact of PE in obstetrics, hence the key issues in the management of PE includes, screening women at high risk, preventing recurrences and to offer specific preventive measures. Early and optimal management of women at high risk can be done by accurate prediction of PE. For prediction of preeclampsia, numerous tests have been described either single or in combination, the sensitivity and specificity of these tests need evaluation. Focus of this article is on the currently available biochemical markers which are said to be used in the prediction of PE.

\section{PATHOGENESIS}

The etiology of preeclampsia is unknown. Evidence suggests that the presence of a placenta but not necessarily a fetus is required for the development of this disorder. ${ }^{10}$ The pathogenesis of preeclampsia is not completely clear. It is a multifactorial disease. Several mechanisms have been implicated in the pathogenesis of preeclampsia, including endothelial dysfunction, inflammatory pathway, oxidative stress and the renin-angiotensin system. ${ }^{11-14}$

It has been considered as a two stage disease in which abnormal placentation precedes endothelial dysfunction. ${ }^{15,16}$ In normal placental development. 
the cytotrophoblasts invade the maternal spiral arterioles and transform them from small caliber resistance vessels to high caliber conduit vessels. The beginning of this initial event has occurred around 10-12 week and completed by 18 to 20 week of gestation. During this vascular invasion the cytotrophoblasts differentiate from epithelial phenotype to an endothelial phenotype, a process known as pseudo vasculogenesis. During this process, these make a direct contact with maternal blood. This process involves a considerable number of transcription factors, growth factors and cytokines like VE-cadherin and alpha $\mathrm{v}$ beta-3 integrins. ${ }^{17}$ During pre-eclampsia, the invasive cytotrophoblasts fail to transform epithelial phenotype into endothelial phenotype along with shallow invasion of the spiral arteriole which leads to defective uteroplacental circulation and worsening placental perfusion causing placental ischemia and hypoxia. ${ }^{18}$ All these directly or indirectly damage endothelial cell function. ${ }^{19}$ Generalized endothelial dysfunction with systemic inflammatory response is thought to be the final common pathway that leads to the maternal signs of preeclampsia with de novo hypertension and proteinuria in the second half of pregnancy. ${ }^{20}$

As preeclampsia is very common in pregnancy and carries a high maternal and perinatal morbidity and mortality, a number of methods are tried to predict the development of preeclampsia so that we can identify these women early and appropriate measures can be taken for safe pregnancy outcomes.

Prediction is basically depend on clinical tests, such as blood pressure measurement during the second trimester or 24-hour ambulatory blood pressure monitoring, angiotensin infusion test, roll over test and some more, but these lack sensitivity and specificity. ${ }^{21}$ Many biomarkers have been evaluated for diagnosis of PE which could also help in the accurate prediction of the PE in the first trimester itself. This review thus focuses on the available biomarkers and their utility. Some of them are described below.

\section{Angiogenic factors}

Circulating factors that regulate blood vessel formation and health, referred to as angiogenic factors. Some novel soluble angiogenic factors are identified that are related to the pathogenesis of the disease. ${ }^{22}$ Angiogenic factors are thought to be important in the regulation of placental vascular development. These factors include circulating antiangiogenic proteins such as soluble fms-like tyrosine kinase- 1 (sflt-1) and soluble endoglin (sEng) and proangiogenic protein such as placental growth factor (PlGF) and vascular endothelial growth factor (VEGF). Their receptors, fms-like tyrosine kinase or Flt-1, also known as vascular endothelial growth factor receptor-1 (VEFGR-1), VEGFR-2, Tie-1, and Tie-2, are essential for normal placental vascular development. A strong association between altered circulating angiogenic factors and preeclampsia has been demonstrated by several studies. The higher relative concentration of antiangiogenic factors are believed to trigger vascular endothelial cell injury in the liver, kidney, brain as well as in the placenta. ${ }^{15,23 \text {, }}$ ${ }^{24}$ Some of the factors are described here.

\section{Endoglin}

Endoglin, an antiangiogenic protein has been implicated in the pathogenesis of PE. It is a 180 $\mathrm{kDa}$, homodimeric, type I membrane glycoprotein located on cell surfaces. It is also commonly referred to as CD105, END, FLJ41744, HHT1, ORW and ORW1. It is a part of the transforming growth factor (TGF) beta receptor complex expressed at high levels on vascular endothelial cells and functions as an antiangiogenic factor by binding transforming growth factor b-1 (TGFb-1) and TGFb-3 proteins which are important for angiogenesis. ${ }^{25}$ Several studies have demonstrated that endoglin is expressed in human first trimester decidua cells and is highly upregulated in the syncytiotrophoblast of women with preeclampsia and concentration of its soluble form is increased into the circulation of preeclamptic women. ${ }^{26,27}$ This soluble form of endoglin (sEng) is produced by the proteolytic cleaving action of MMP-14 (Matrix metalloproteinase) in extracellular domain. ${ }^{28,29}$ It acts by antagonizing an angiogenic and vasodilator molecule known as transforming growth factor beta-1, which is important in angiogenesis and also maintain the health of the blood vessels. Due to this, cell lining the blood vessels begin to sicken and die, blood pressure increases and blood vessels leak protein into the tissues and urine. ${ }^{30}$ It is an important protein for tumor growth, survival and metastasis of cancer cells to other locations in the body.

In human pregnancy, alterations in serum sEng antedate clinical symptoms of preeclampsia by several months before the onset of disease. ${ }^{31}$ Because high levels of serum sEng are released into the human circulation prior to the clinical manifestations of 
pre-eclampsia, this glycoprotein has been proposed recently as a serum diagnostic biomarker for preeclampsia. ${ }^{32}$ Levine et al evaluated the potential of sEng in combination with other pro- and antiangiogenic factors like PIGF, sFlt1 for the prediction of pre-eclampsia. ${ }^{31}$ The study implied that the sFlt-1: PlGF ratio and more specifically (sFlt-1+sEng): PlGF is a stronger predictor of pre-eclampsia in comparison to individual markers. ${ }^{33}$

\section{Vascular Endothelial Growth Factor (VEGF), Placental Growth Factor (PIGF)}

Among the various angiogenic factors expressed by the placenta, VEGF and PlGF play a very important role. ${ }^{34}$ VEGFs are a family of structurally related dimeric proteins whose members include VEGF-A, VEGF-B, VEGF-C, VEGF-D and PIGF. VEGF play an important role to promote sustenance, migration and differentiation of endothelial cells and also maintain the vascular permeability. VEGF interact with VEGFR-2 and VEGFR-1 on the placental endothelial cells. ${ }^{35}$ Several studies have reported that serum concentration of VEGF is reduced in preeclamptic patients. That is why the activity of sFlt-1 (a soluble form of VEGF receptor-1 or sVEGFR-1) is upregulated in pre-eclamptic conditions. ${ }^{36}$ Increased levels of free serum sFlt1 bind with both VEGF and PlGF, thereby neutralizing them, and subsequently their levels in circulation reduced. ${ }^{36}$ There is also decreased production of VEGF by circulating $\mathrm{T}$ and natural killer cells in pre-eclampsia, it also play a role in endothelial dysfunction which is characteristic of the maternal syndrome of the disease. ${ }^{37}$ Although for prediction of PE, VEGF has been studied as a promising marker but it could not be detected by many available ELISA kit because its circulatory levels are very low. ${ }^{38,39}$ To overcome this limitation, highly sensitive ELISA kits can be used. ${ }^{39}$

One of the most important members of VEGF family is placental growth factor (PlGF). It also has an important role in angiogenesis and placental vasculature. ${ }^{40}$ Placental trophoblasts are the major source of PIGF. PIGF-1, PIGF-2, PIGF-3, and PIGF4 are the different isoforms of the PlGF. PIGF binds only to VEGFR- $1{ }^{41}$ In women who are destined to develop PE, the splice variant of VEGFR-1, the sFlt-1, readily neutralizes the PlGF, hence its level in the serum reduces..$^{34,38,40}$ Various studies have demonstrated that maternal serum levels of PIGF are lower in both early and late onset PE. ${ }^{40,42}$ Various studies suggest, the best method for prediction of PE is PIGF: sFlt-1 ratio. ${ }^{40}$

\section{Soluble FMS-like tyrosine kinase -1 (SFLT-1)}

It is an anti-angiogenic soluble form of type-1 VEGF receptor. It results from alternative splicing of Flt-1 receptor mRNA, which is an endothelial receptor for VEGF and PIGF. sFlt-1 consists of an extracellular ligand binding domain of Flt-1, but lacks the transmembrane and intracellular signaling domain. This secretory form circulates freely in the serum where it binds and neutralizes the VEGF and PIGF. ${ }^{43}$ When compared with control subjects, the women who develop PE, a significant rise in serum levels of sFlt-1 was shown by several studies. ${ }^{36}$ The sFlt1 specific ELISA kits are used for estimation of its serum levels. ${ }^{36}$ Baumann et al reported the predictive role of sFlt1 and sEngin PE. ${ }^{44}$ Levine et al also found that higher levels of serum sFlt-1 are predictive of PE. ${ }^{31}$ However, some studies showed the lower specificity and poor predictive value of sFlt-1 in the early stages of pregnancy. ${ }^{40}$

\section{Inhibin-A and Activin-A}

These glycoproteins are produced by the fetoplacental unit. In patients who subsequently developed PE, higher serum levels of these glycoproteins are found in their first trimester ${ }^{45}$ Hence, these can be used in prediction of PE.

\section{Pregnancy Associated Plasma Protein-A (PAPP-A)}

It is 1628 amino acid peptide. It is mainly produced by the trophoblastic cells. It has a role in cleavage of insulin like growth factor binding proteins. It has a role in regulation of fetal growth. Some studies have shown that plasma levels of PAPP-A has decreased in all trimesters of pregnancy, some other studies indicate that the levels of PAPP-A were significantly reduced in the early onset PE while in case of late onset $\mathrm{PE}$ the levels did not differ from the control group. ${ }^{46,47}$ Hence, PAPP-A is not useful in predicting late onset $\mathrm{PE}$ and larger trials are required to confirm these preliminary predictions. ${ }^{36}$

\section{Neutrophil Gelatinase-Associated Lipocalin (NGAL)}

Neutrophil gelatinase-associated lipocalin (NGAL), is a $25 \mathrm{kDa}$ protein and belongs to the lipocalins family. ${ }^{48,49}$ It is also known as lipocalin-2, siderocalin, uterocalin and $24 \mathrm{p} 3 .^{48,49}$ It was first identified as a matrix protein of specific granules of human 
neutrophils. Its expression is highly upregulated in damaged epithelial cells, during inflammation, neoplastic conditions, cardiovascular diseases, infections and renal disorders. ${ }^{50}$ NGAL can be detected in urine within two hours of kidney damage, hence it is considered as the best and the earliest markers of acute kidney damage. ${ }^{50,51}$ In some recent studies serum level of NGAL was found to be increased at the end of second trimester in women who subsequently developed PE compared to control group..$^{47,49,52}$ A positive correlation of serum NGAL was found with the systolic and diastolic blood pressure and with proteinuria. ${ }^{38,47,49}$ Hence serum NGAL can be used as a reliable biomarker for early prediction of pre-eclampsia.

\section{Placental Protein 13 (PP-13)}

Placental protein 13 (PP13) is a $32 \mathrm{kDa}$ dimericprotein. It was first isolated in 1983 from the syncytiotrophoblast of the placenta by Bohn et al..$^{54,55}$ It was identified as a member of the galectin super family, which has an important role in placental implantation and remodelling of maternal arteries. ${ }^{38,56}$ To perform this function PP13 has a carbohydrate binding domain, to which two proteins AnnexinII and Actin-beta bind. In normal pregnancy. PP13 levels are gradually increasing while abnormally low levels of PP13 were found in first trimester of women who subsequently developed PE, compared with controls. ${ }^{53,56,57}$ Hence, it can be used as serum biomarker for prediction of PE. ${ }^{53}$

Nicolaides et al demonstrated that the combination of serum PP13 levels and uterine artery pulsating index measured by Doppler ultrasonography have a good prediction rate to identify the patients having the risk of developing pre-eclampsia in the first trimester. ${ }^{56}$ PP13 specific ELISA kits are used to measure the serum PP13 levels with good sensitivity and specificity. ${ }^{53,56}$ Hence, by using serum PP13 alone or in combination with Doppler studies, early identification of high risk patients can be done and we have a good opportunity for implementation of treatment strategies. ${ }^{53,56-58}$
Pentraxin-Related Protein 3 (PTX3) PTX3 is TNF-inducible gene 14 protein (TSG14)). This protein is encoded by the $P T X 3$ gene in humans. ${ }^{59}$ Maternal plasma levels of PTX3 was found to be elevated in preeclamptic women in comparison to control group, supporting the excessive maternal inflammatory response to pregnancy as one of the etiology of PE. ${ }^{60}$

\section{$\mathrm{P}$-selectin}

$\mathrm{P}$-selectin is a protein encoded by the SELP gene in humans. ${ }^{61}$ Platelet activation in PE is reflected by elevated levels of platelets exposing P-selectin. In plasma, a non-cell bound (soluble) form of P-selectin is present. Elevated levels of this soluble form have been reported in PE.

\section{Other tests}

Laboratory tests for oxidative response, i.e. malondialdehyde along with antioxidants have been assessed, including assays for uric acid, urinary kallikrein, fibronectin and cytokines but till date no test was found relevant. ${ }^{62-66}$ Because no single marker effectively predicts the risk of PE, hence in clinical practice, the current trend is to test a combination of markers. Larger studies are required to label a single molecule as a biomarker for the early prediction of PE.

\section{CONCLUSION}

Our understanding about etiology and pathogenesis of PE has been improved a lot in last decade. Several studies have been done and a lot of biomarkers were studied for prediction and diagnosis of PE such as anti- angiogenic factors like serum soluble endoglin, sFlt-1, sEng and pro-angiogenic factors like VEGF, PIGF. These biomarkers have certain drawbacks like, lack of high sensitive assay kits, inability to predict onset of the disease during initial stages of gestation, low specificity, lack of prognostic value and many other issues. Hence further studies are required with larger population and with more precise and advanced techniques.

\section{REFERENCE}

1. Steegers EA, von Dadelszen P, Duvekot JJ, Pijnenborg R. Preeclampsia. Lancet. 2010;376:631-44.

2. Ghulmiyyah L, Sibai B. Maternal mortality from preeclampsia/ eclampsia. Semin. Perinatol. 2012;36:56-9.
3. Duley L. Pre-eclampsia and the hypertensive disorders of pregnancy. Br Med Bull. 2003; 67:161-76.

4. Gifford PA, August G, Cunningham. Report of the national high blood pressure education program working group on high blood pressure in pregnancy. Am J Obstet Gynecol 2000; 183:S1-S22. 
5. Maynard SE, Min JY, Merchan J, Lim JH, Li J, Mondal S et al. Excess placental soluble fms-like tyrosine kinase 1 (sFlt1) may contribute to endothelial dysfunction hypertension, and proteinuria in preeclampsia. J Clin Invest 2003;111:649-58.

6. Redman CWG, Sacks GP, Sergeant I. Preeclampsia: an excessive maternal inflammatory response to pregnancy. Am J Obstet Gynecol. 1999; 180:499-506.

7. Noronha Neto C, de Souza AS, Amorim MM. Pre-eclampsia treatment according to scientific evidence. Rev Bras Ginecol Obstet. 2010;32:459-68.

8. Arora R, Ganguli RP, Swain S, Oumachigui A, Rajaram P. Determinants of maternal mortality in eclampsia in India. Aust N Z J Obstet Gynaecol.1994;34:537-9.

9. Suhail M, Faizul Suhail M, Khan H. Role of vitamins C and $\mathrm{E}$ in regulating antioxidant and pro-oxidant markers in preeclampsia. J Clin Biochem Nutr. 2008;43:210-20.

10. Shah DM. Preeclampsia: new insights, current opinion in Nephrology and Hypertension. Curr Opin Nephrol Hypertens 2007;16:213-20.

11. Combs CA, Katz MA, Kitzmiller JL, Brescia RJ. Experimental preeclampsia produced by chronic constriction of the lower aorta: validation with longitudinal blood pressure measurements in conscious rhesus monkeys. Am J Obstet Gynecol.1993;69:215-23.

12. Gervasi MT, Chaiworapongsa T, Pacora P, Naccasha N, Yoon BH, Maymon E, Romero R. Phenotypic and metabolic characteristics of monocytes and granulocytes in preeclampsia. Am J Obstet Gynecol. 2001;185:792-797.

13. Many A, Hubel CA, Fisher SJ, Roberts JM, Zhou Y. Invasive cytotrophoblasts manifest evidence of oxidative stress in preeclampsia. Am J Pathol. 2000;156:321-31.

14. Nielsen AH, Schauser KH, Poulsen K. Current topic: the uteroplacental renin-angiotensin system. Placenta. 2000;21:468-77.

15. Mutter WP, Karumanchi SA. Molecular mechanism of preeclampsia. Microvasc Res. 2008;75:1-8.

16. Redman CW, Sergeant IL. Placental stress \& preeclampsia: A revised view. Placenta. 2009;30(Suppl.A):S38-S42.

17. Zhou Y, Fisher SJ, Janatpour M, Genbacev O, Dejana E, Wheelock $\mathrm{M}$ et al. Human cytotrophoblasts adopt a vascular phenotype as they differentiate a strategy for successful endovascular invasion? J Clin Invest. 1997;99:2139-51.

18. Maynard SE, Karumanchi SA. Angiogenic factors and preeclampsia. Semin Nephrol. 2011;31:33-46.

19. Zhou Y, Damsky CH, Fisher SJ. Preeclampsia is associated with failure of human cytotrophoblasts to mimic a vascular adhesion phenotype. One cause of defective endovascular invasion in this syndrome? J Clin Invest. 1997;99:2152-64.

20. Staff AC, x Anne Cathrine StaffSearch for articles by this author Affiliations Department of Obstetrics and Gynecology, Ullevaal University Hospital and Faculty of Medicine, University of Oslo, Oslo, Norway

21. Braekke K, Johnsen GM, Karumanchi SA, Harsem KA. Circulating concentrations of soluble endoglin (CD105) in fetal and maternal serum and in amniotic fluid in preeclampsia. Am J Obstet Gynecol. 2007. 197(2):176.e1-6.

22. Conde-Agudelo A, Villar J, Lindheimer M. World Health Organization: systematic review of screening tests for PE. Obstet Gynecol. 2004;104:1367-91.

23. Powe CE, Levine RJ, Karumanchi SA. Preeclampsia, a disease of the maternal endothelium: the role of antiangiogenic factors and implications for later cardiovascular disease. Circulation. 2011;123:2856-69.

24. Maynard SE, Min JY, Merchan J, Lim KH, Li J, Mondal S et al. Excess placental soluble fms-like tyrosine kinase 1 (sflt1) may contribute to endothelial dysfunction, hypertension, and proteinuria in preeclampsia. J Clin Invest. 2003;111:649-58.

25. Tsatsaris V, Goffin F, Munaut C, Brichant JF, Pignon MR, Noel A et al. Overexpression of the soluble vascular endothelial growth factor receptor in preeclamptic patients: pathophysiological consequences. J Clin Endocrinol Metab. 2003;88:5555-63.

26. Venkatesha S, Toporsian M, Lam C, Hanai J, Mammoto $\mathrm{T}$, Kim YM et al . Soluble endoglin contributes to the pathogenesis of preeclampsia. Nat Med. 2006;12:642-9.

27. Cheifetz S, Bello' n T, Cale' s C, Vera S, Bernabeu C, Massague' J et al. Endoglin is a component of the transforming growth factor-beta receptor system in human endothelial cells. J Biol Chem.1992;267:19027-30.

28. Vailhe' B, Kapp M, Dietl J, Arck P. Human first-trimester decidua vascular density: an immunohistochemical study using VE-cadherin and endoglin as endothelial cell markers. Am J Reprod Immunol. 2000;44:9-15.

29. Venkatesha S, Toporsian M, Lam C, Hanai J, Mammoto T, Kim $\mathrm{YM}$ et al. Soluble endoglin contributes to the pathogenesis of preeclampsia. Nat Med. 2006;12:642-9.

30. Raab U, Velasco B, Lastres P, Letamendi'a A, Cale' s C, Langa $\mathrm{C}$ et al. Expression of normal and truncated forms of human endoglin. Biochem J. 1999;339:579-88.

31. Lo' pez-Casillas F, Cheifetz S, Doody J, Andres JL, Lane WS, Massague'J. Structure and expression of the membrane proteoglycan betaglycan, a component of the TGF-beta receptor system. Cell. 1991;67:785-95.

32. Levine RJ, Lam C, Qian C, Yu KF, Maynard SE, Sachs BP et al. Soluble endoglin and other circulating antiangiogenic factors in preeclampsia. N Engl J Med. 2006;355:992-1005.

33. Robinson CJ, Johnson DD . Soluble endoglin as a second trimester marker for preeclampsia. Am J Obstet Gynecol. 2007;197:174-6.

34. Levine RJ, Maynard SE, Qian C, Lim KH, England LJ, $\mathrm{Yu} \mathrm{KF}$ et al. Circulating angiogenic factors and the risk of preeclampsia. N Engl J Med. 2004;350:672-83.

35. Agarwal I, Karumanchi SA. Preeclampsia and the antiangiogenic state. Pregnancy Hypertens. 2011;1:17-21.

36. Romero R, Nien JK, Espinoza J, Todem D, Fu W, Chung H et al. A longitudinal study of angiogenic (placental growth factor) and anti-angiogenic (soluble endoglin and soluble vascular endothelial growth factor receptor-1) factors in normal pregnancy and patients destined to develop preeclampsia and deliver a small-for-gestational-age neonate. J Matern Fetal Neonatal Med. 2008;21:9-23.

37. Lapaire O, Shennan A, Stepan H. The preeclampsia biomarkers soluble fms-like tyrosine kinase-1 and placental growth factor: current knowledge, clinical implications and future application. Eur J Obstet Gynecol Reprod Biol. 2010;151:122-9.

38. Molvarec A, Ito M, Shima T, Yoneda S, Toldi G, Stenczer $\mathrm{B}$ et al. Decreased proportion of peripheral blood vascular endothelial growth factor-expressing $\mathrm{T}$ and natural killer cells in preeclampsia. Am J Obstet Gynecol. 2010;203:567.

39. Grill S, Rusterholz C, Zanetti-Dällenbach R, Tercanli S, Holzgreve W, Hahn S et al. Potential markers of preeclampsia - a review. Reprod Biol Endocrinol. 2009;7:70-84. 
40. Lam C, Lim K-H, Karumanchi SA. Circulating angiogenic factors in the pathogenesis and prediction of preeclampsia. Hypertension. 2005;46:1077-85.

41. Hertig A, Liere P. New markers in preeclampsia. Clin Chim Acta. 2010;411:1591-5.

42. Desai J, Holt-Shore V, Torry RJ, Caudle MR, Torry DS. Signal transduction and biological function of placenta growth factor in primary human trophoblast. Biol Reprod. 1999;60:887-92.

43. Molvarec A, Szarka A, Walentin S, Szucs E, Nagy B, Rigó J Jr. Circulating angiogenic factors determined by electrochemiluminescence immunoassay in relation to the clinical features and laboratory parameters in women with pre-eclampsia. Hypertens Res. 2010;33:892-8.

44. Wang A, Rana S, Karumanchi SA. Preeclampsia: the role of angiogenic factors in its pathogenesis. Physiology (Bethesda). 2009;24:147-58.

45. Baumann MU, Bersinger NA, Mohaupt MG, Raio L, Gerber S, Surbek DV. First-trimester serum levels of soluble endoglin and soluble fms-like tyrosine kinase-1 as first-trimester markers for late-onset preeclampsia. Am J Obstet Gynecol. 2008;199:266.

46. Akolekar R,Minekawa R, Veduta A, Romero XC, Nicolaides $\mathrm{KH}$. Maternal plasma inhibin A at 11-13 weeks of gestation in hypertensive disorders of pregnancy. Prenat Diagn. 2009;29(8):753-60.

47. Spencer K, Cowans NJ, Nicolaides KH. Low levels of maternal serum PAPP-A in the first trimester and the risk of PE. Prenat Diagn 2008;28(1):7-10.

48. D’Anna R, Baviera G, Giordano D, Russo S, Dugo N, Santamaria A et al. First trimester serum PAPP-A and NGAL in the prediction of late-onset pre-eclampsia. Prenat Diagn. 2009;29:1066-8.

49. Hawkins R. New biomarkers of acute kidney injury and the cardio-renal syndrome. Korean J Lab Med. 2011;31:72-80.

50. Giasson J, Li GH, Chen Y. Neutrophil gelatinase-associated lipocalin (NGAL) as a new biomarker for non-acute kidney injury (AKI) diseases. Inflamm Allergy Drug Targets. 2011;10:272-82.

51. Uttenthal LO. NGAL: a marker molecule for the distressed kidney? Clin Lab Int. 2005;29:39-41.

52. Mishra J, Dent C, Tarabishi R, Mitsnefes MM, Ma Q, Kelly Q et al. Neutrophil gelatinase-associated lipocalin (NGAL) as a biomarker for acute renal injury after cardiac surgery. Lancet. 2005;365:1231-8.

53. D'Anna R, Baviera G, Giordano D, Todarello G, Corrado F, Buemi M. Second trimester neutrophil gelatinase-associated lipocalin as a potential prediagnostic marker of preeclampsia. Acta Obstet Gynecol Scand. 2008;87:1370-3.

54. D’Anna R, Baviera G, Giordano D, Todarello G, Russo $\mathrm{S}$, Recupero $\mathrm{S}$ et al. Neutrophil gelatinase-associated lipocalin serum evaluation through normal pregnancy and in pregnancies complicated by preeclampsia. Acta Obstet Gynecol Scand. 2010;89:275-8.

55. Costa FS, Murthi P, Keogh R, Woodrow N. Early screening for preeclampsia. Rev Bras Gynaecol Obstet. 2011;33:36775.

56. Bohn H, Kraus W, Winckler W. Purification and characterization of two new soluble placental tissue proteins (PP13 and PP17). Oncodev Biol Med. 1983;4:343-50.

57. Nicolaides KH, Bindra R, Turan OM, Chefetz L, Sammar M, Meiri $\mathrm{H}$ et al. A novel approach to first-trimester screening for early pre-eclampsia combining serum PP-13 and Doppler ultrasound. Ultrasound Obstet Gynecol. 2006;27:13-7.

58. Carty DM, Delles C, Dominiczak AF. Novel biomarkers for predicting preeclampsia. Trends Cardiovasc Med. 2008;18:186-94.

59. Huppertz B, Kawaguchi R. First trimester serum markers to predict preeclampsia. Wien Med Wochenschr. 2012;162:1915.

60. Breviario F, d'Aniello EM, Golay J, Peri G, Bottazzi B, Bairoch A et al. Interleukin-1-inducible genes in endothelial cells. Cloning of a new gene related to C-reactive protein and serum amyloid P component. J Biol Chem. 1992; 267(31):22190-7.

61. Cetin I, Cozzi V, Papageorghiou AT, Maina V, Montanelli A, Garlanda C et al. First trimester PTX3 levels in women who subsequently develop PE and fetal growth restriction. Acta Obstet Gynecol Scand. 2009;88(7):846-9.

62. Ryan US, Worthington RE. Cell-cell contact mechanisms. Curr Opin Immunol. 1992;4 (1):33-7.

63. Conde-Agudelo A, Villar J, Lindheimer M. World Health Organization: systematic review of screening tests for PE. Obstet Gynecol. 2004;104:1367-91. 